\title{
Noise-induced changes in red blood cell velocity in lateral wall vessels of the rat cochlea
}

\author{
W.S. Quirk, B.D. Shapiro, J.M. Miller and A.L. Nuttall \\ Kresge Hearing Research Institute, The University of Michigan, Ann Arbor, Michigan, U.S.A.
}

(Received 5 July 1990; accepted 10 October 1990)

\begin{abstract}
The effects of loud sound on the microvasculature of the cochlea are not well characterized or understood. Morphological changes in the stria vascularis and changes in blood flow are known to occur during or following sound stimulation, however the effects on cochlear blood flow appear to be complex. Studies have shown that noise exposure may produce increases in blood flow, decreases in blood flow, or no measureable change in blood flow. These inconsistent results probably reflect the various noise exposure parameters, the animal model used, and could be a function of the specific procedures utilized to assess blood flow changes.

The purpose of the current study was to investigate the effects of one specific class of sound exposure (high intensity noise) on red blood cell velocity in the capillaries of the second turn of the rat cochlea using intravital microscopy. This class of sound exposure was selected in order to attempt a confirmation of previous findings of increased blood flow (Perlman and Kimura, 1962) using the quantitative technique of red blood cell velocity measurement. Following determination of pre-exposure red blood cell velocities in capillaries of the rat cochlea second turn, animals were exposed to $133 \mathrm{~dB}$ or $110 \mathrm{~dB}$ broad-band noise for ten minutes. The red blood cell velocity was recorded continuously during the exposure. Exposure to both sound intensities disrupted stable and orderly baseline flow patterns and resulted in overall intensity-dependent increases in red blood cell velocity. Qualitatively, we observed aggregations of red blood cells, local vasoconstriction and directional reversals of red blood cell flow during noise exposure at both intensities. These results may represent the interaction of several mechanisms that participate in the control of blood flow in the cochlea during noise exposure.
\end{abstract}

Noise; Red blood cell velocity; Stria vascularis; Vasoconstriction; Homeostasis

\section{Introduction}

The effects of loud sound on the microvasculature of the cochlea are not well characterized or understood. Morphological changes in the stria vascularis and changes in blood flow are known to occur (e.g. Duvall et al., 1971) however, studies have shown that noise exposure can result in an assortment of changes which include changes in microvascular parameters such as vessel size or red blood cell distributions during or following exposure to loud sound. A study by Perlman and Kimura (1962) showed an increase in microscopically observed blood flow velocity in stria vas-

Correspondence to: Wayne S. Quirk, Kresge Hearing Research Institute, The University of Michigan, 1301 East Ann Street, Ann Arbor, MI 48109-0506, U.S.A. cularis vessels of the guinea pig and an impaired or abolished microphonic response following exposure to $135-155 \mathrm{~dB}$ noise. Ryan et al. (1988) found histologic and autoradiographic evidence of small increases in cochlear blood flow in response to $85 \mathrm{~dB}$ SPL, but not at higher intensities. Prazma et al. $(1983,1987)$ also observed an increase in cochlear blood flow in response to noise at $113 \mathrm{~dB}$ for $13 \mathrm{~min}$ and $115 \mathrm{~dB}$ for $60 \mathrm{~min}$, as indicated by trapped microspheres.

Histological studies have generally revealed changes in the cochlear vasculature that are consistent with decreased cochlear blood flow, such as swelling of endothelial cells, constriction of capillaries and alterations in red blood cell spacing (Hawkins, 1971)). This work, implicating various forms of vasoconstriction, has been corroborated by a number of investigations (Duvall et al., 1974; Vertes, 1979; Axelsson et al., 1981; Den- 
gerink et al., 1985). Physiological measurements of cochlear blood flow using laser Doppler flowmetry (Thorne and Nuttall, 1988; Scheibe et al., 1990) have been consitent with these histological findings for the sound intensities used.

Adding to this disparate body of literature are a group of microsphere studies which have yielded evidence for no alterations of blood flow following exposure to loud sound (Hultcrantz et al., 1979a; Hultcrantz et al., 1979b). Additionally, measures such as changes in oxygen tension (Nuttall et al., 1981) and hydrogen clearance (Maas et al., 1978) have failed to find evidence of changes in blood flow in response to sound of moderate intensity.

These inconsistent results concerning the effects of sound may be related to the type and level of sound used and quite possibly are a function of differences in techniques used to measure cochear blood flow, since each is sensitive to different microvascular parameters. Additional information on the effects of sound may provide insight into the sensitivity of these measures, as well as insight into the interactions of the underlying mechanisms of noise-induced pathology. Thus, it was the purpose of the current study to investigate just one distinct class of sound (high intensity noise) on red blood cell velocity in vessels of the stria vascularis in rat cochlea. Preliminary testing in our laboratory, as well as the work of Morimitzu et al. (1965) Hultcrantz (1979) and Angleborg et al. (1979) have failed to demonstrate any measurable changes in blood flow at intensity levels ranging from 85-105 dB SPL. Therefore, we chose 133 dB SPL and $110 \mathrm{~dB}$ SPL for the present study.

\section{Methods}

\section{Subjects}

Mature, male Wistar-Kyoto (WKY) rats were obtained from Harlan-Sprague Dawley, Inc. All procedures were reviewed and approved by the animal welfare committee at the University of Michigan and all subjects were housed in AAALAC approved facilities.

\section{Preparations and materials}

Each animal was anesthetized with thiopentol $(75 \mathrm{mg} / \mathrm{ml}$ ) and body temperature was monitored with a rectal probe and maintained at $38 \pm 1^{\circ} \mathrm{C}$ with a heating pad. The animal was placed in a heated head holder and a tracheotomy was performed allowing the insertion of a ventilation tube. A catheter was placed in the right carotid artery for monitoring systemic blood pressure and in the right jugular vein for infusion of a mixture of fluorescently labeled dextran (FITC-dextran 2\%) and bovine albumin (3\%, in $0.50 \mathrm{ml} 0.15 \mathrm{M} \mathrm{NaCl}$ ). The bulla was exposed using a ventrolateral approach and opened for access to the cochlea. The tympanic membrane and ossicular chain were left intact.

A small fenestra was created in the second turn of the cochlea for observation of external wall blood circulation. Observations of blood flow were accomplished utilizing a customized intravital microscope as described by Nuttall (1987). Briefly, a long-working-distance objective lens permitted direct observation of blood vessels in the cochlea. Images were received by a silicon intensified video camera (Dage MTI model 66) and recorded on video tape for subsequent processing. The vascular network was displayed on a video monitor at a magnification of about $1000 \mathrm{x}$. Red blood cell velocity was assessed using a video photometric analyzer (Instruments for Physiology and Medicine, Model 202) and a velocity tracker (Instruments for Physiology and Medicine, model 102). Estimated vessel diameter was determined using a custom video image processing package (Miles and Nuttall, 1988).

The sound source consisted of a function generator, a band-pass filter, attenuator and a power amplifier. Sound was delivered from the speaker through a closed tube to a speculum positioned into the opening of the external auditory canal. Sound levels were measured using a Bruel and Kjaer 4134 half-inch condensor microphone.

\section{Protocol}

Baseline blood pressure, red blood cell velocity and vessel diameter were determined during a 15 min control observation period. One group of animals $(N=6)$ was exposed to $133 \mathrm{~dB}$ broadband noise for $10 \mathrm{~min}$ and a second group ( $N=13)$ to $110 \mathrm{~dB}$ broad-band noise. These measures were monitored continuously during the stimulation period and for a $5 \mathrm{~min}$ recovery period. 


\section{Statistical analysis}

Changes in red blood cell velocity were analyzed using an analysis of variance (ANOVA). Red blood cell velocities for all vessels were measured once each by independent observers and compared for the reported data.

\section{Results}

The systemic blood pressure of animals exposed to either noise intensity showed little change during noise stimulation. Mean baseline blood pressure for all animals was $97.6 \pm 2.7 \mathrm{mmHg}$ and mean blood pressure during noise was $95.1 \pm 5.9$ mmHg. Repeated measures ANOVA indicated there was no sample bias in red blood cell velocities between groups.

\section{Velocity changes}

\section{$133 \mathrm{~dB}$ SPL broad-band noise}

Red blood cell velocity varied across vessels and was stable and orderly during the baseline condition as has been previously reported in the guinea pig model (Axelsson et al., 1990). Exposure to $133 \mathrm{~dB}$ SPL broad-band noise induced large oscillatory variations in observable lateral wall vessels. Fig. 1 shows changes in red blood cell velocity in 3 vessels in a representative animal for baseline, stimulation and recovery conditions. $\mathrm{Ob}-$ served vessels typically showed a substantial increase followed by oscillations toward or around baseline velocity. The recovery condition was

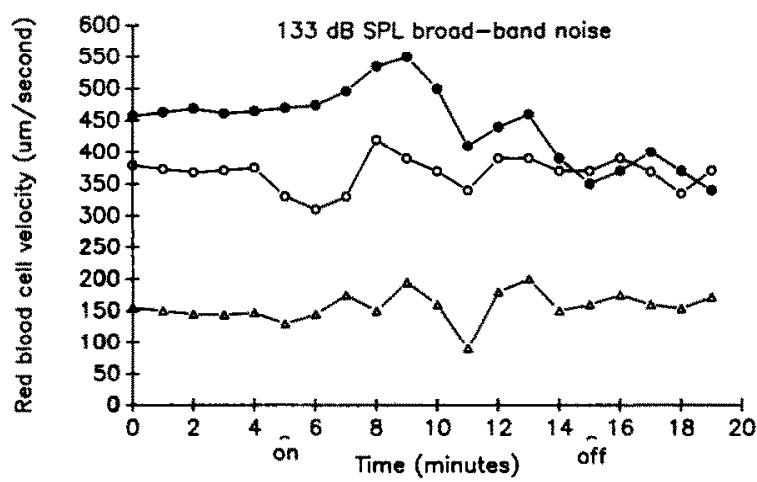

Fig. 1. Baseline, stimulation and recovery periods for 3 capillaries in one representative animal in response to $133 \mathrm{~dB}$ SPL broad-band noise.
TABLE I

MEAN ( \pm SEM) BASELINE, NOISE (133 dB SPL BROADBAND) AND RECOVERY RED BLOOD CELL VELOCITIES FOR SECOND TURN LATERAL WALL VESSELS OF WISTAR-KYOTO RATS

\begin{tabular}{|c|c|c|c|c|}
\hline \multirow{2}{*}{$\begin{array}{l}\text { Animal } \\
\text { number }\end{array}$} & \multirow{2}{*}{$\begin{array}{l}\text { Estimated } \\
\text { diameter } \\
(\mu \mathrm{m})\end{array}$} & \multicolumn{3}{|c|}{ Red blood cell velocity $(\mu \mathrm{m} / \mathrm{s})$} \\
\hline & & baseline & noise & recovery \\
\hline \multirow[t]{2}{*}{0051} & 5.3 & $119.7(4.3)$ & $117.6 \quad(5.9)$ & \\
\hline & 10.6 & $376.3(5.2)$ & $391.5 \quad(7.6)$ & \\
\hline 0061 & 9.6 & $175.0(14.4)$ & $147.1(11.5)$ & \\
\hline \multirow[t]{2}{*}{0062} & 10.5 & $181.7(10.1)$ & $203.5(8.4)$ & $205.0(16.1)$ \\
\hline & 9.6 & $278.3(4.4)$ & $291.0(10.3)$ & $302.1(11.6)$ \\
\hline \multirow[t]{2}{*}{0063} & 9.7 & $203.3(39.5)$ & $331.0(39.6)$ & \\
\hline & 10.5 & $155.5(29.5)$ & $260.6(29.3)$ & \\
\hline \multirow[t]{3}{*}{0151} & 10.0 & $373.3(14.5)$ & $364.0(11.0)$ & $365.0(16.1)$ \\
\hline & 9.1 & $463.3(20.3)$ & $472.5(16.1)$ & $363.3(18.6)$ \\
\hline & 6.4 & $148.3(4.4)$ & $152.5(10.6)$ & $165.5(5.0)$ \\
\hline \multirow[t]{3}{*}{0152} & 5.2 & $400.2(4.0)$ & $355.0(15.0)$ & $346.7(12.0)$ \\
\hline & 8.8 & $157.5(17.5)$ & $151.1(5.3)$ & $126.7(4.4)$ \\
\hline & 7.4 & $240.0(10.1)$ & $246.7(6.9)$ & $210.0(5.0)$ \\
\hline$N=6$ & $N=13$ & & & \\
\hline
\end{tabular}

characterized by flow patterns that were not as stable as baseline conditions, yet less oscillatory than during exposure to noise. These patterns of red blood cell velocity resulted in a significant change during the protocol $(\mathrm{F}=1.88, \mathrm{df}=12,132$, $P<0.05$ ) and resulted in overall mean velocity increases in 9 vessels and decreases in 4 vessels (Table I). These patterns were not obviously related to other vascular features, such as the size of the vessel or the direction of flow. Mean $( \pm S E M)$ red blood cell velocities of all vessels for baseline, stimulation and recovery conditions are listed in Table I.

\section{0 dB SPL broad-band noise}

Baseline measures of red blood cell velocity in these animals was also stable and orderly. Exposure to $110 \mathrm{~dB}$ broad-band noise induced variations in red blood cell velocity that were slightly different from baseline $(\mathrm{F}=1.52$, $\mathrm{df}=12,336$, $P=0.10$ ). Fig. 2 depicts the changes in time in red blood cell velocity in 3 vessels of a representative animal. Patterns of red blood cell velocity during stimulation were characterized by small oscillations around original baseline measures. Variation in velocity for the group resulted in increases in 


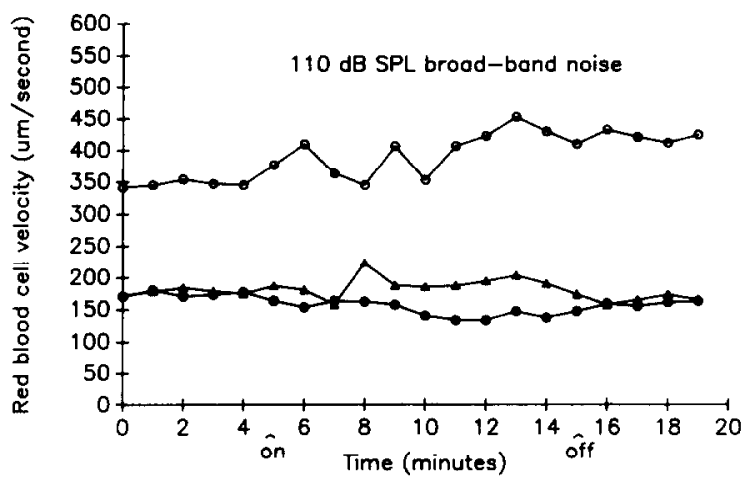

Fig. 2. Baseline, stimluation and recovery periods for 3 capillaries in one representative animal in response to $110 \mathrm{~dB}$ SPL broad-band noise.

overall mean velocity in 19 vessels and decreases in 10 vessels. Again, these responses were not obviously related to other vascular features. Mean ( \pm SEM) changes for all vessels in baseline, stimulation and recovery conditions are listed in Table II.

Two way ANOVA indicated there was a statistical difference between velocity changes measured in animals exposed to $110 \mathrm{~dB}$ broad-band noise as compared with animals exposed to 133 $\mathrm{dB}$ broad-band noise $(\mathrm{F}=2.28, \mathrm{df}=12,468, P<$ 0.01 ).

\section{Qualitative observations}

In all noise exposed vessels we observed aggregations of red blood cells early in the noise stimulation period. And, in many cases these aggregations of red blood cells became trapped at or near vessel bifurcations. Interestingly, when these red blood cells became trapped, presumably as a result of the red blood cell aggregations and vessel constriction, the flow in effected vessels reversed, perhaps finding an alternative route in the capillary bed. Upon termination of the noise stimulation, flow direction returned to normal. Fig. 3 is a representative example of this response in one group of vessels during exposure to $110 \mathrm{~dB}$ SPL broad-band noise. Fig. 3 (A) depicts a pattern of flow prior to noise exposure. The direction of flow is denoted by the arrows. Fig. 3 (B) shows an aggregation of red blood cells trapped in a vessel at a time point three min into the ten min noise
TABLE II

MEAN ( \pm SEM) BASELINE, NOISE (110 dB SPL BROADBAND) AND RECOVERY RED BLOOD CELL VELOCITIES FOR SECOND TURN LATERAL WALL VESSELS OF WISTAR-KYOTO RATS

\begin{tabular}{|c|c|c|c|c|}
\hline \multirow{2}{*}{$\begin{array}{l}\text { Animal } \\
\text { number }\end{array}$} & \multirow{2}{*}{$\begin{array}{l}\text { Estimated } \\
\text { diameter } \\
(\mu \mathrm{m})\end{array}$} & \multicolumn{3}{|c|}{ Red blood cell velocity $(\mu \mathrm{m} / \mathrm{s})$} \\
\hline & & baseline & noise & recovery \\
\hline \multirow[t]{2}{*}{0041} & 5.6 & $367.5 \quad(7.7)$ & $386.4(10.8)$ & \\
\hline & 6.8 & $181.0(20.9)$ & 209.7 (4.4) & $204.3(11.8)$ \\
\hline \multirow[t]{2}{*}{0043} & 7.8 & $172.5(5.6)$ & $188.1 \quad(7.6)$ & \\
\hline & 6.8 & $205.5 \quad(6.9)$ & $245.6 \quad(5.2)$ & \\
\hline \multirow[t]{2}{*}{0044} & 5.7 & $228.8(18.9)$ & $287.8 \quad(5.5)$ & $317.4 \quad(2.1)$ \\
\hline & 7.2 & $111.6 \quad(9.1)$ & $207.6 \quad(8.4)$ & $157.5(16.7)$ \\
\hline \multirow[t]{2}{*}{0050} & 5.3 & $180.0(14.1)$ & $223.1(12.3)$ & $186.8(7.8)$ \\
\hline & 7.3 & 247.7 (7.9) & $245.5(10.4)$ & $157.5(7.1)$ \\
\hline \multirow[t]{3}{*}{0052} & 10.6 & $347.3(20.6)$ & $396.8(11.3)$ & $421.5(11.5)$ \\
\hline & 5.3 & 178.7 (4.4) & 188.7 (5.9) & $165.0(8.0)$ \\
\hline & 7.3 & 176.7 & $148.8 \quad(3.9)$ & $180.0(10.1)$ \\
\hline \multirow[t]{3}{*}{0053} & 6.7 & $327.5(14.7)$ & 333.4 (3.9) & $360.0(3.0)$ \\
\hline & 5.4 & $278.2(13.4)$ & $254.6 \quad(9.4)$ & 306.5 (3.5) \\
\hline & 6.5 & $287.2(31.8)$ & $217.3 \quad(9.3)$ & $263.5(36.5)$ \\
\hline 0054 & 5.3 & $192.5(13.5)$ & $168.7(6.7)$ & \\
\hline 0055 & 10.6 & $347.3(20.6)$ & $396.8(11.3)$ & $421.5 \quad(5.0)$ \\
\hline 0060 & 9.6 & $178.3(6.0)$ & $227.2(14.1)$ & \\
\hline \multirow[t]{3}{*}{0111} & 10.2 & $201.7 \quad(6.9)$ & $251.5(17.1)$ & \\
\hline & 5.6 & $146.7 \quad(6.7)$ & $143.0 \quad(5.4)$ & \\
\hline & 10.5 & $263.3 \quad(3.3)$ & $249.0(12.9)$ & \\
\hline \multirow[t]{2}{*}{0112} & 10.1 & $243.3 \quad(6.7)$ & $227.0(14.4)$ & $185.0(10.4)$ \\
\hline & 10.5 & $220.0(17.3)$ & $230.5 \quad(6.6)$ & $193.3(20.3)$ \\
\hline \multirow[t]{3}{*}{0150} & 5.7 & $163.3(18.6)$ & $203.0(10.9)$ & $163.8(12.0)$ \\
\hline & 9.8 & $356.7(28.3)$ & $411.1 \quad(8.8)$ & $456.7 \quad(3.3)$ \\
\hline & 8.8 & $123.8 \quad(8.8)$ & $123.0 \quad(5.9)$ & 123.3 \\
\hline \multirow[t]{4}{*}{0153} & 5.2 & $273.3(38.4)$ & $279.5(13.8)$ & $286.7(24.0)$ \\
\hline & 9.7 & $258.3(11.7)$ & $252.5(11.3)$ & $230.0(10.0)$ \\
\hline & 8.7 & $120.0 \quad(5.0)$ & $129.5 \quad(5.3)$ & $153.3(16.4)$ \\
\hline & 9.8 & $231.7(11.7)$ & $200.5 \quad(8.6)$ & $223.3(12.0)$ \\
\hline$N=13$ & $N=29$ & & & \\
\hline
\end{tabular}

stimulation period (filled arrow). These trapped red blood cells appeared to cause a reversal in flow in nearby vessels (as shown by the arrows). In Fig. 3 (C) the original flow pattern is re-established following termination of the noise exposure.

\section{Discussion}

These results generally indicate that stimulation with broad-band sound at both $133 \mathrm{~dB}$ SPL and $110 \mathrm{~dB}$ SPL has a differential effect on the capillaries of the second turn of the rat cochlea. Following stable baseline measures, exposure to 

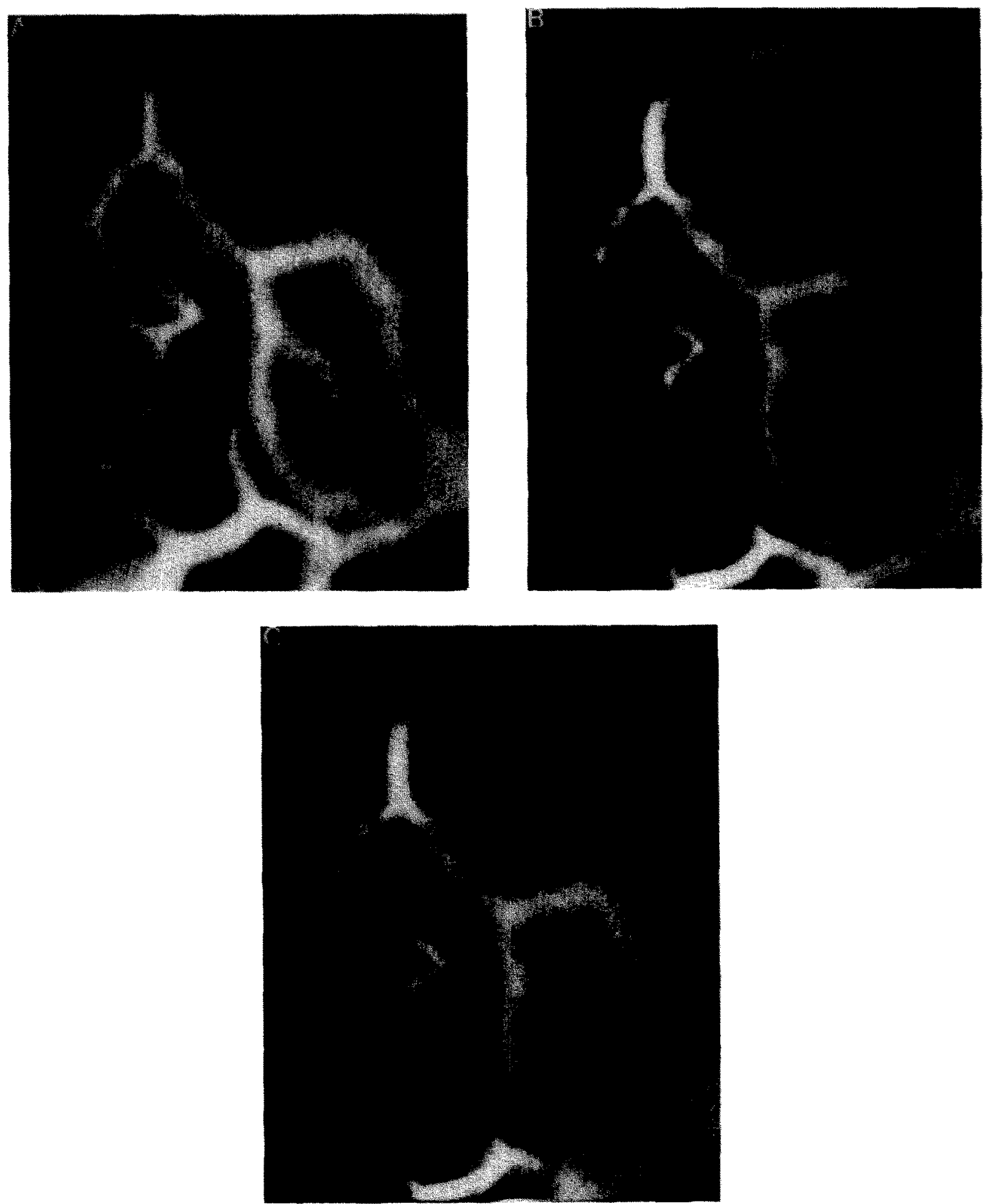

Fig. 3. This figure is a representative example of the effects of $110 \mathrm{~dB}$ broad-band noise on a group of stria vascularis vessels in a guinea pig cochlea. Photograph (A) depicts a pattern of flow prior to noise exposure. The direction of flow is denoted by the arrows. Photograph (B) shows an aggregation of red blood cells trapped in a vessel at a time point three min into the ten min noise stimulation period (filled arrow). These trapped red blood cells appeared to cause a reversal in flow in nearby vessels (as shown by the arrows). In photograph (C) the original flow pattern is reestablished following termination of the noise exposure. 
both intensities produced large oscillatory changes in red blood cell velocity. These variations resulted in significant increases in some vessels, while other vessels were observed to decrease slightly during the same exposure period. Additionally, stimulation at these two noise intensities induced aggregations of red blood cells and alterations in the flow direction.

These differential effects may reflect specific and separate local control of cochlear blood flow as has been previously suggested (Axelsson et al., 1981; Dengerink et al., 1985; Quirk et al., 1988; Ryan et al., 1988). Interestingly, previous reports have observed stable patterns of flow despite variations in velocity due to alterations in systemic blood pressure (Axelsson et al., 1990). The current study confirmed this for the control state, however the differential patterns of flow observed during stimulation may represent changes specific to noise.

The effects of loud sound on cochlear vessels is not well characterized in the literature (for review see Axelsson and Vertes, 1982) and subsequently the underlying mechanisms are also unclear. Proposed mechanisms responsible for cochlear microcirculatory alterations include a general circulatory response (Axelsson and Vertes, 1982), mechanical action (Axelsson and Vertes, 1982), metabolic exhaustion (Bohne, 1976), increased-metabolic demand (Ryan et al., 1988), hormonal influence (Dengerink et al., 1985) and ionic changes in perilymph and endolymph (Bohne, 1976). Based upon this disparate literature, the number of proposed mechanisms, as well as the results of the current study, it may be that the alterations in cochlear circulation in response to loud sound are not the result of any single mechanism.

Therefore, one possible interpretation of the present results is that first, the increases in red blood cell velocity reflect an increased metabolic demand of cochlear tissues. It has previously been proposed that increased metabolic demands are associated with increased regional blood flow in the cochlea in response to $133 \mathrm{~dB}$ noise (Perlman and Kimura, 1962) and 85 dB noise (Ryan et al., 1988). In studies of metabolic demands, glucose utilization has been shown to increase in response to noise stimulation below $90 \mathrm{~dB}$ SPL (Canlon and Schacht, 1983).
Secondly, the decreasing phase of the oscillatory pattern of velocity observed in these external wall vessels in the current study may be the result of shunting (Hawkins, 1971) to high demand areas, such as sensory and neural structures (Ryan et al., 1988). While there is no direct evidence concerning the mechanism mediating decreases in flow it may be the result of the local action of circulating vasoactive hormones released during noise exposure. Previous studies have demonstrated that exposure to noise results in increased circulating levels of vasoactive hormones such as angiotensin (Wright et al., 1981) and oxytocin (Fruhstorfer et al., 1988). Additionally, angiotensin II (Quirk et al., 1988) and vasopressin (McClaren et al., 1990) have been shown to induce decreases in cochlear blood flow when infused into the supplying vessels of the cochlea. Therefore, the decreases in flow observed in certain vessels in response to both high intensity noise levels and the decrease in red blood cell velocity noted following the initial increase in response to $133 \mathrm{~dB}$ SPL may reflect local regulation. Furthermore, this regulatory response may be mediated by the local activity of hormones released during prolonged exposure to noise.

In summary, during pre-exposure conditions red blood cell velocity appears to be stable and orderly. Exposure to loud sound results in oscillatory disruptions in red blood cell velocity and overall intensity-dependent increases in velocity. These patterns of red blood cell velocity may represent the interaction of metabolic demands and hormonally mediated local regulation in the cochlear vasculature.

\section{Acknowledgements}

This work was supported by NIH Fellowship grant F32-DC00017 and NIH RO1-DC00105.

\section{References}

Angelborg, C., Hultcrantz, E. and Beausang-Linder, M. (1979) The cochlear blood flow in relation to noise and cervical sympathectomy. Adv. Otorhinolaryngol. 25, 41-48.

Axelsson, A., Vertes, D. and Miller, I.M. (1981) Immediate noise effects on the cochlea vasculature in the guinea pig. Acta Oto-Laryngol. 91, 237-246.

Axelsson, A. and Vertes, D. (1982) Histological findings in cochlear vessels after noise. In: R.P. Hamernik, D. Hender- 
son, and R. Salvi (Eds.), New Perspectives on Noise-Induced Hearing Loss, Raven Press, New York, pp. 49-67.

Axelsson, A., Nuttall, A.L., Miller, J.M. (1990) Observations of cochlear microcirculation using intravital microscopy. Acta Otolaryngol. (Stockh). 109, 263-270.

Bohne, B.A. (1976) Mechanisms of noise damage in the inner ear. In: D. Henderson, R.P. Hamernik, D.S. Dosanj, and J.H. Mills (Eds.), Effects of Noise on Hearing, Raven Press, New York, pp. 41-68.

Dengerink, H.A., Miller, J.M., Axelsson, A, Vertes, D. and Van Dalfsen, P. (1985) The recovery of vascular changes following brief noise exposure. Acta Otolaryngol. (Stockh). 100, 19-25.

Duvall, A.J., Ward, W.D. and Lauhala, K.E. (1974) Stria ultrastructure and vessel transport in acoustic trauma. Ann. Oto. 83, 498-514.

Fruhstorfer, B., Pritsch, M.G. and Fruhstorfer, H. (1988) Effects of daytime noise load on the sleep-wake cycle and endocrine patterns in man. 1. 24 hours neurophysiological data. Int. J. Neurosci. 39, 197-209.

Granger, H.J, Shelling, M.E., Lewis, R.E., Zawieja, D.C. and Meininger, C.J. (1988) Physiology and pathobiology of the microcirculation. Am. J. Otolaryngol. 9, 264-277.

Hawkins, J.E. (1971) The role of vasoconstriction in noise-induced hearing loss. Ann. Otol. Rhinol. Laryngol. 80, 903913.

Hillerdal, M., Jansson, B., Engstrom, B., Hultcrantz, E. and Borg, E. (1987) Cochlear blood flow in noise-damaged ears. Acta Otolaryngol, (Stockh). 104, 270-278.

McLaren, G.M., Coleman, J.K., Quirk, W S., Dengerink, H.A. and Wright, J.W. Effects of arginine vasopressin and Pmp', O-Me-Tyr ${ }^{2}-\left[\mathrm{Arg}^{8}\right]$-vasopressin infused into the anterior inferior cerebellar artery on cochlear blood flow in the normotensive rat. (in preparation).

Miles, F.P. and Nuttall, A.L. (1989) In vivo capillary diameters in the stria vascularis and spiral ligament of the guinea pig cochlea. Hear. Res. 33, $191-200$.
Morimitzu, T., Matsuo, K. and Suga, F. (1965) Behavior of the cochlear blood flow. Ann. Otol. Rhinol. Laryngol. 74, 2242.

Nuttall, A.L. (1987) Techniques for the observation and measurement of red blood cell velocity in vessels of the guinea pig cochlea. Hear. Res. 27, 111-119.

Nuttall, A.L., Hultcrantz, E. and Lawrence, M. (1981) Does loud sound influence iniracochlear oxygen tension? Hear. Res, 5, 285-293.

Perlman, H.B, and Kimura, R. (1962) Cochlear blood flow in acoustic trauma. Acta OtoLaryngol. 54, 99-119.

Prazma, J, Rodgers, G.K. and Pilisbury, H.C. (1983) Cochlear blood flow: Effect of noise. Arch. Otolaryngol. 109, 611615.

Prazma, J. Vance, S.G., Bolster, D.E., Pilsbury, H.C and Postma, DS. (1987) Cochlear blood flow: Effect of noise at 60 minutes' exposure. Arch. Otolaryngol. Head Neck Surg. $113,36-39$.

Ryan, A.F., Axelsson, A., Myers, R. and Woolf, N.K. (1988) Changes in cochlear blood flow during acoustic stimulation as determined by ${ }^{14} \mathrm{C}$-iodoantipyrine autoradiography. Acta Otolaryngol. (Stockh). 105, 232-241.

Scheibe, F., Haupt, H., Nuttall, A.L. and Ludwig, C. (1990) Laser Doppler measurements of cochlear blood flow during loud sound presentation. Eut. Arch. Otorhinolaryngol. 247, 84-88.

Thome P.R. and Nuttall, A.L. (1987) Laser Doppler measurements of cochlear blood flow during loud sound exposure in the guinea pig. Hear. Res. 27, 1-10.

Wright, J.W., Dengerink, H.A., Thomupson, P. and Morseth, S. (1981) Plasma angiotensin II changes with noise exposure at three levels of ambient temperature. J. Acoust. Soc. Am. $70,1353-1356$. 